\title{
THE INFLUENCE OF HYDROGEN EMBRITTLEMENT ON THE MECHANICAL PROPERTIES OF DUAL-PHASE STEEL DP600
}

\author{
Petra VÁŇOVÁ, Jaroslav SOJKA, Tatána KULOVÁ, Kateřina KONEČNÁ, \\ Anastasia SPINU \\ VSB - Technical University of Ostrava, Ostrava, Czech Republic, EU \\ petra.vanova@vsb.cz
}

https://doi.org/10.37904/metal.2019.858

\begin{abstract}
The susceptibility to hydrogen embrittlement of a dual-phase steel DP600 with ferritic-martensitic microstructure was studied on previously hydrogenated samples by slow strain rate tensile tests (SSRT). The samples were subjected to electrolytic hydrogen charging in $0.05 \mathrm{M}$ sulfuric acid solution with the addition of $\mathrm{KSCN}$ at a current density of 1 and $5 \mathrm{~mA} \cdot \mathrm{cm}^{-2}$ during 4,8 and 24 hours. Due to the presence of hydrogen in the steel microstructure, a decrease of elongation at fracture from $24 \%$ to $15 \%$ was observed. Index of hydrogen embrittlement describing the relative change of elongation at fracture due to hydrogen was calculated as $38 \%$ for the following hydrogen charging conditions: current density $1 \mathrm{~mA} \cdot \mathrm{cm}^{-2}$ and time 8 hours. The index of hydrogen embrittlement decreased with increasing the hydrogenation time and the current density likely due to the formation of a corrosion layer that prevented further penetration of hydrogen into the steel. Changes of yield strength and tensile strength at a low current density were not observed, but at higher current densities, the yield strength increased by more than $40 \mathrm{MPa}$. Fracture surfaces of the tensile test bars were subjected to fractographic analysis. Transgranular ductile fracture was a predominant kind of fracture for all testing conditions, even for hydrogenated tensile bars. The proportion of quasi-cleavage fracture typical of hydrogen embrittlement was very low.
\end{abstract}

Keywords: Hydrogen embrittlement, dual-phase steel, slow strain rate test (SSRT)

\section{INTRODUCTION}

Dual-phase (DP) steels belong to the Advanced High Strength Steels (AHSS) group with high strength and relatively good elongation at fracture. They are used in the automotive industry to design parts that require high strength values, high impact energy absorption, as well as good weldability and formability. DP steels consist of two phases: ferritic matrix and martensitic islets. The soft ferritic matrix is generally continuous, giving these steels excellent elongation at fracture. When these steels are subjected to a deformation, the stress is concentrated in the lower-strength ferritic matrix that surrounds the martensite islets. DP steels have a higher carbon content (up to $0.1 \%$ ) compared to other types of automotive sheets as well as increased content of elements as manganese, which are able to stabilize austenite. Also, a higher silicon content (up to $0.8 \%$ ) supports not only the formation of the basic ferritic matrix but also its strengthening. Increasing the martensitic phase volume fraction generally increases strength. DP steels are produced by controlled cooling from an austenitic phase (in finished rolled products) or from a two-phase ferritic and austenitic phase (for annealed hot and cold rolled products) and by a subsequent rapid cooling to transform austenite into martensite. Due to the manufacturing process, a small amount of additional phases (bainite and residual austenite) can be present [1-3].

However, technological operations related to the surface treatment of sheets to increase their corrosion resistance, which include acid pickling, pose a risk of hydrogen embrittlement as hydrogen can penetrate into the steel during acid pickling [4]. 
The aim of this work is to investigate the influence of hydrogen on mechanical properties of DP steel. DP600 steel samples will be subjected to electrolytic hydrogenation to simulate hydrogen penetration into the material. The influence of hydrogen on the mechanical properties of steel will be evaluated using the SSRT (Slow Strain Rate Test) method on pre-charged samples. Fracture surfaces of steel before and after hydrogenation will be investigated by the scanning electron microscopy.

\section{EXPERIMENTAL PART}

\subsection{Material description and microstructure}

The mechanical properties that are characteristic of DP600 steel are the tensile strength in the range of $580-700 \mathrm{MPa}$, the yield strength of $330-440 \mathrm{MPa}$ and the elongation at fracture minimally $21 \%$. This steel is characterized by its ability to absorb impact energy and good fatigue strength. Therefore, this type of material is suitable for the manufacture of automotive parts such as longitudinal beams, cross beams and reinforcements. The chemical composition of the test material is shown in Table 1. The chemical composition was determined by the GDOES method on a GDA 750 Spectruma device. The chemical composition is correlated with the normalized content of elements (max. $0.15 \%$ C, max. $2.5 \% \mathrm{Mn}$ and max. $0.8 \% \mathrm{Si}$ ) [6].

Table 1 The chemical composition of DP600 steel (wt.\%)

\begin{tabular}{|c|c|c|c|c|c|c|c|c|c|c|}
\hline $\mathbf{C}$ & $\mathbf{M n}$ & $\mathbf{S i}$ & $\mathbf{P}$ & $\mathbf{S}$ & $\mathbf{C r}$ & $\mathbf{A l}$ & $\mathbf{N i}$ & $\mathbf{C o}$ & $\mathbf{C u}$ & $\mathbf{T i}$ \\
\hline 0.04 & 1.20 & 0.08 & 0.046 & 0.003 & 0.57 & 0.03 & 0.02 & 0.005 & 0.013 & 0.005 \\
\hline
\end{tabular}

Metallographic samples were studied on Olympus GX51 optical microscope (marked LM) in the longitudinal direction to the rolling in a polished and etched condition (Nital etch). Samples for metallographic observation were taken from the base material, $3.35 \mathrm{~mm}$ thick sheet, and thinned $1.5 \mathrm{~mm}$ tensile specimen. According to ČSN ISO 4967, the non-metallic inclusions at 100x magnification were determined in the polished state in the longitudinal direction. Inclusions of index D2-2.5 (globular oxide inclusions) and DS0.5 (individual globular inclusions) were determined in the base material. The size of the individual globular inclusions ranged from $4 \mu \mathrm{m}$ to $10 \mu \mathrm{m}$. After etching, a segregation band with a higher content of non-metallic inclusions was identified in the base material in the centre of the sheet thickness. Elongated sulphide inclusions were up to $150 \mu \mathrm{m}$ in length. In the case of the tensile test sample, this segregation band was identified near the surface (Figure 1). This fact suggests a method of preparing a tensile test specimen where the base material was thinned by grinding from $3.35 \mathrm{~mm}$ thickness to $1.5 \mathrm{~mm}$ thickness on a magnetic grinder, resulting in the position of the segregation band being shifted from the centre of the original material near the edge. As described above, the DP steel microstructure contains a ferritic matrix with martensitic islets. The examined DP steel consists predominantly of ferrite and martensitic islets with an occasional occurrence of bainite blocks (Figure 2).

\subsection{Mechanical properties}

Samples with a width of $10 \mathrm{~mm}$ and an initial measured length for determination of elongation at fracture $L_{0}=50 \mathrm{~mm}$ were loaded on a tensile test machine from the company $\mathrm{w}+\mathrm{b} 100 \mathrm{kN}$ up to a failure with a speed of $0.5 \mathrm{~mm} \cdot \mathrm{min}^{-1}$, that is $10^{-4} \mathrm{~s}^{-1}$. In this way, both the hydrogen-free and hydrogenated samples were tested.

In order to determine the susceptibility of DP600 steel to hydrogen embrittlement, the tensile test bars were electrolytically charged and immediately thereafter were subjected at a slow strain rate tensile test. The electrolytic hydrogen charging was carried out in the $0.05 \mathrm{M}$ sulfuric acid solution $\left(\mathrm{H}_{2} \mathrm{SO}_{4}\right)$ with 1 gram of KSCN as hydrogen poison per litre of electrolyte. The test bar was connected in the electrical circuit as a cathode, and the anode was a tungsten mesh covered with a platinum layer. The hydrogenation time was determined as 4 hours, 8 hours and 24 hours at two current densities of $1 \mathrm{~mA} \cdot \mathrm{cm}^{-2}$ and $5 \mathrm{~mA} \cdot \mathrm{cm}^{-2}$. 


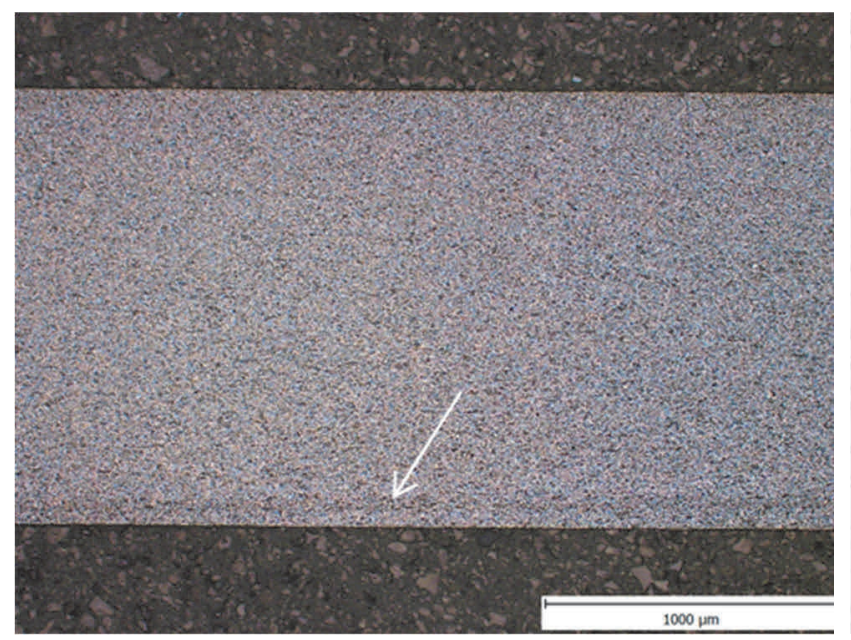

Figure 1 DP steel microstructure, surface segregation band, longitudinal direction, etched Nital (LM).

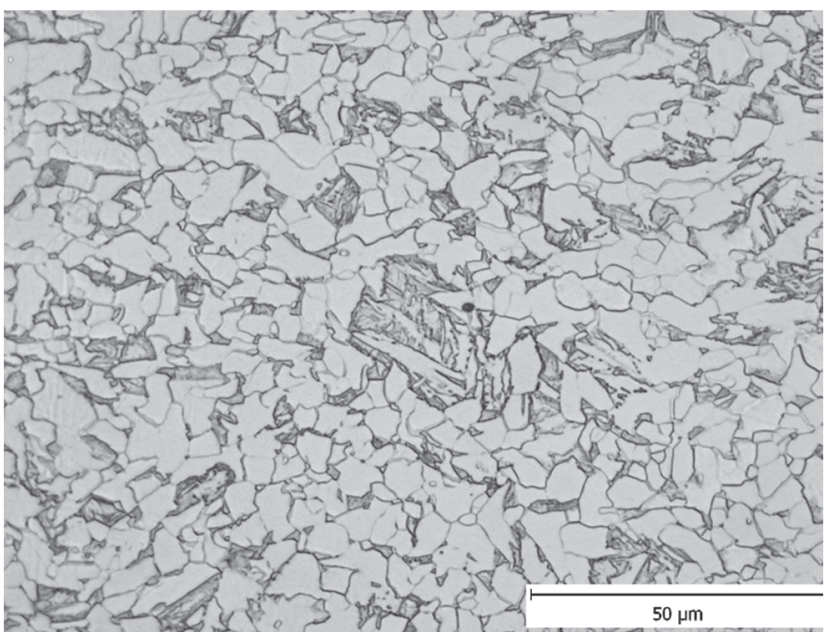

Figure 2 Detail of microstructure of DP steel (ferrite, martensite and bainite), longitudinal direction, etched Nital (LM).

SSRT (Slow strain rate test) is a test that is used to study stress corrosion cracking. This is a slow strain test compared to conventional tensile tests applied at a constant elongation rate in a given environment. The loading rate for SSRT tests ranges from $10^{-7}$ to $10^{-3} \mathrm{~s}^{-1}$ according to ISO 7539-7:2005 Corrosion of metals and alloys - Stress corrosion testing - Part 7: Method for slow strain rate testing [5]. After hydrogen charging, the tensile bar was immediately placed in a testing machine and a tensile test was performed to the final fracture. The need to start loading as soon as possible after the end of hydrogenation is explained by the ability of hydrogen to diffuse from the sample volume, which could affect the measured values. After the tensile test, an evaluation was carried out to determine the effect of hydrogen on the strength properties (yield strength $R_{p 0.2}$ and tensile strength $R_{m}$ ) and plastic properties (elongation at fracture $A_{50}$ ). The relative elongation at fracture change was expressed by the hydrogen embrittlement index IE by equation $1[4,7]$ :

$I E=\frac{A_{0}-A_{H}}{A_{0}} \cdot 100 \%$

where $A_{0}$ is the elongation at fracture of the sample without hydrogen (\%) and $A_{H}$ is the elongation at fracture of the sample with hydrogen (\%).

The calculated hydrogen embrittlement index can be found in Table 2. As can be deduced from this Table, the effect of hydrogen on the strength properties is minimal, but the hydrogen had the greatest impact on the plastic properties of the material as elongation $\Delta L$, and hence elongation at fracture $A_{50}$. Comparison of the results after electrolytic charging with the initial state shows that the presence of hydrogen in the steel provoked the elongation at fracture decrease from $23.8 \%$ to the lowest value of $14.8 \%$, corresponding to $37.8 \%$ hydrogen embrittlement index. In the case of lower current densities, neither the yield strength nor the tensile strength was affected, but with a higher current density and longer hydrogenation time, the yield strength was increased by $50 \mathrm{MPa}$. The effect of hydrogen on the tensile strength of DP600 steel was not found. The highest values of hydrogen embrittlement indexes were observed after hydrogenation of 4 and 8 hours at a current density of $1 \mathrm{~mA} \cdot \mathrm{cm}^{-2}$, namely $36.1 \%$ and $37.8 \%$. At longer hydrogenation times and higher current densities, hydrogen embrittlement indexes were found to be lower, in the range from $21.0 \%$ to $26.5 \%$. This behaviour may be affected by oxidation of the sample surface during the hydrogenation process and by the formation of a corrosion layer that prevents further hydrogen penetration into the steel and thus hydrogen embrittlement. 
Figure 3 shows the behaviour of the material after pre-charging at two current densities for 8 hours compared to the tensile test in the initial state without hydrogen.

Table 2 Values of yield strength $R_{p 0.2}$, tensile strength $R_{m}$, elongation $\Delta L$, elongation at fracture $A_{50}$ and the hydrogen embrittlement index IE for non-hydrogenated and hydrogenated samples

\begin{tabular}{|c|c|c|c|c|c|}
\hline $\begin{array}{l}\text { Current density } \\
\text { Time of charging }\end{array}$ & $\begin{array}{c}R_{p 0,2} \\
(\mathrm{MPa})\end{array}$ & $\begin{array}{c}R_{m} \\
(\mathrm{MPa})\end{array}$ & $\underset{(\mathrm{mm})}{\Delta L}$ & $\begin{array}{l}A_{50} \\
(\%)\end{array}$ & $\begin{array}{l}\text { IE } \\
(\%)\end{array}$ \\
\hline $\begin{array}{c}\text { Initial state } \\
\text { without H }\end{array}$ & $406 \pm 13$ & $626 \pm 9$ & $11.9 \pm 0.3$ & $23.8 \pm 0.5$ & - \\
\hline $\begin{array}{c}1 \mathrm{~mA} \cdot \mathrm{cm}^{-2} \\
4 \text { hours }\end{array}$ & $416 \pm 2$ & $630 \pm 8$ & $7.6 \pm 0.1$ & $15.2 \pm 0.2$ & $36.1 \pm 0.8$ \\
\hline $\begin{array}{c}1 \mathrm{~mA} \cdot \mathrm{cm}^{-2} \\
8 \text { hours }\end{array}$ & $397 \pm 16$ & $619 \pm 5$ & $7.4 \pm 0.2$ & $14.8 \pm 0.0$ & $37.8 \pm 0.0$ \\
\hline $\begin{array}{l}1 \mathrm{~mA} \cdot \mathrm{cm}^{-2} \\
24 \text { hours }\end{array}$ & $416 \pm 5$ & $612 \pm 1$ & $9.3 \pm 0.4$ & $18.6 \pm 0.8$ & $21.8 \pm 3.4$ \\
\hline $\begin{array}{c}5 \mathrm{~mA} \cdot \mathrm{cm}^{-2} \\
4 \text { hours }\end{array}$ & $443 \pm 6$ & $629 \pm 9$ & $8.8 \pm 0.8$ & $17.5 \pm 1.5$ & $26.5 \pm 6.3$ \\
\hline $\begin{array}{l}5 \mathrm{~mA} \cdot \mathrm{cm}^{-2} \\
8 \text { hours }\end{array}$ & $457 \pm 28$ & $633 \pm 2$ & $9.4 \pm 0.8$ & $18.8 \pm 1.6$ & $21.0 \pm 3.2$ \\
\hline
\end{tabular}

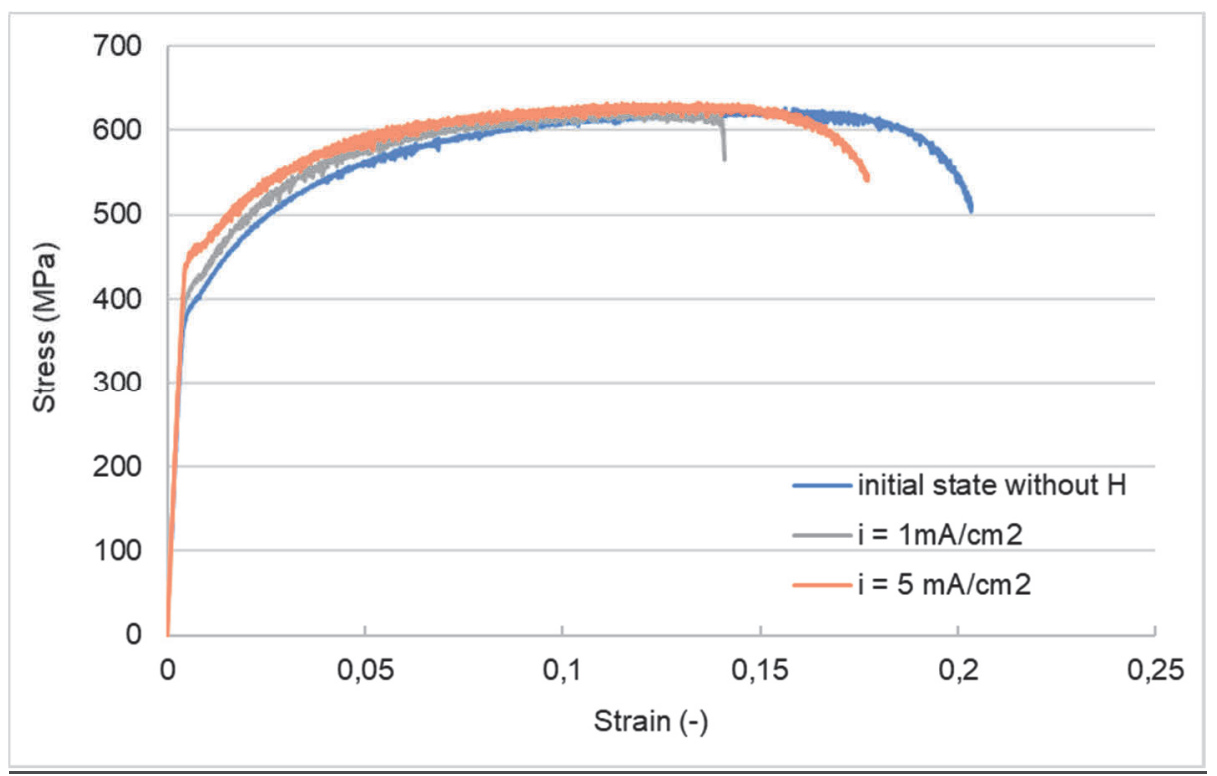

Figure 3 Stress-strain dependence for samples pre-charged at a current density of $1 \mathrm{~mA} \cdot \mathrm{cm}^{-2}$ and $5 \mathrm{~mA} \cdot \mathrm{cm}^{-2}$ for time of 8 hours compared to the initial state without hydrogen

\subsection{Fractographic analysis}

After hydrogenation, visible blisters were found on the surface of the tensile test specimens. A longitudinal metallographic cut was made at these locations. It is evident that the crack spread below the surface at the site of the segregation band with a higher concentration of non-metallic inclusions (Figures 4) and can be correlated with the hydrogen induced cracking mechanism (HIC). Surface blisters after the charging process, were also identified by scanning electron microscopy (Figure 5). Figure 5 shows the morphology of a surface blister where the area around the crack is formed by a quasi-cleavage fracture. 
Using a scanning electron microscope JEOL 6490LV (SEM) in the secondary electron mode (SE), a fractographic analysis of the tensile test samples was performed in the initial state and in the individual pre-charging modes. The fracture area of the sample in the initial state corresponded only to transgranular ductile fracture. Compared to other types of materials, such as TRIP steels [8], a large embrittlement has not been observed on the fractured surfaces of the DP steel after hydrogenation, but regions formed by quasi-cleavage fracture have been locally manifested (Figure 6). These areas, approximately 80-100 $\mu \mathrm{m}$ in diameter, called fish eyes, were most commonly observed around non-metallic inclusions (Figure 7).

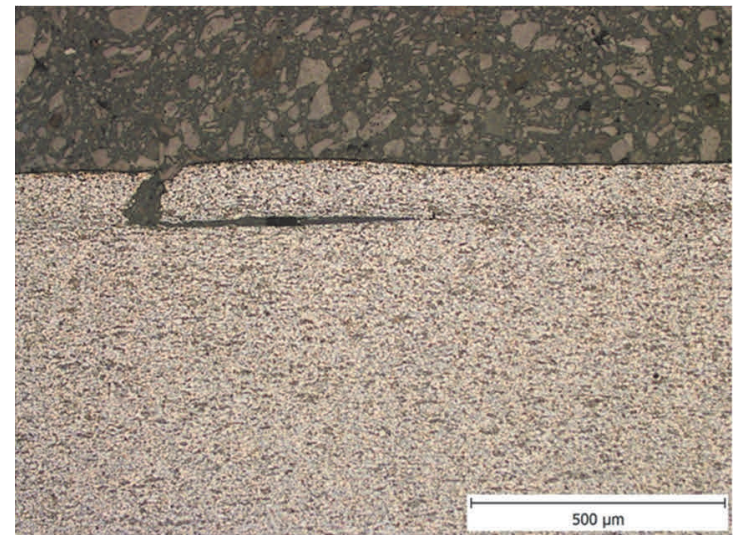

Figure 4 Surface blister, segregation band, longitudinal direction, etched Nital (LM)

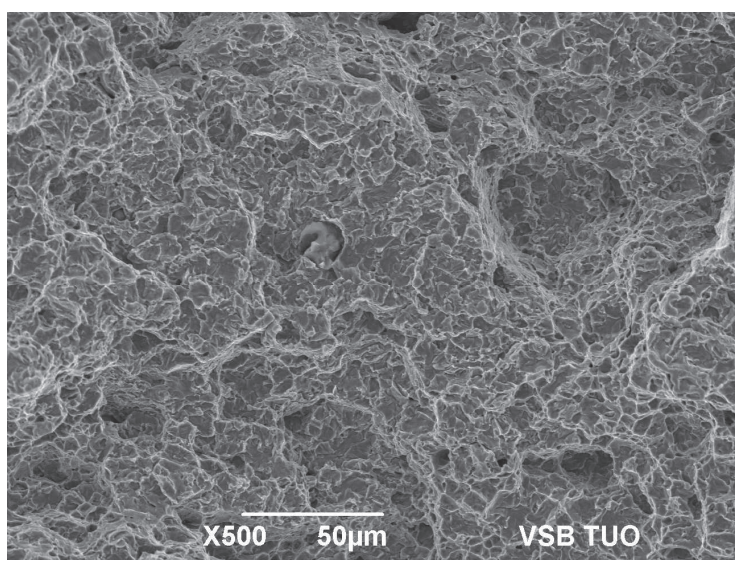

Figure 6 Fracture surface after hydrogenation for 4 hours at $i=5 \mathrm{~mA} \cdot \mathrm{cm}^{-2}(\mathrm{SEM}-\mathrm{SE})$

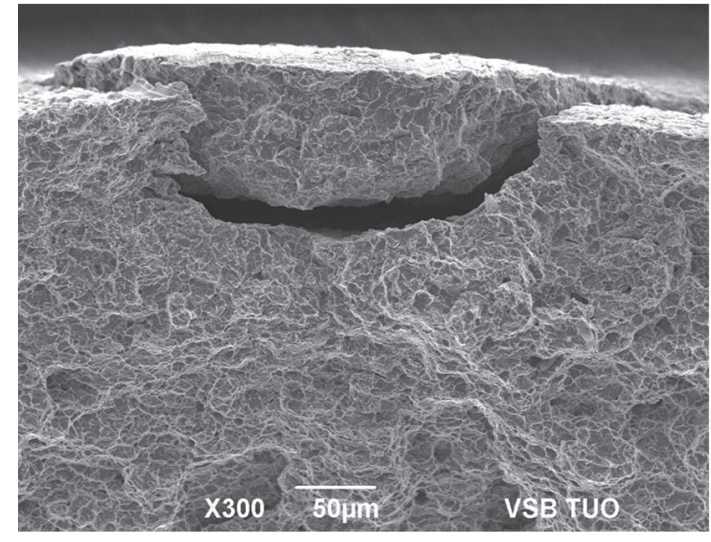

Figure 5 A detailed view of the surface blister, a quasi-cleavage fracture around the crack (SEM-SE)

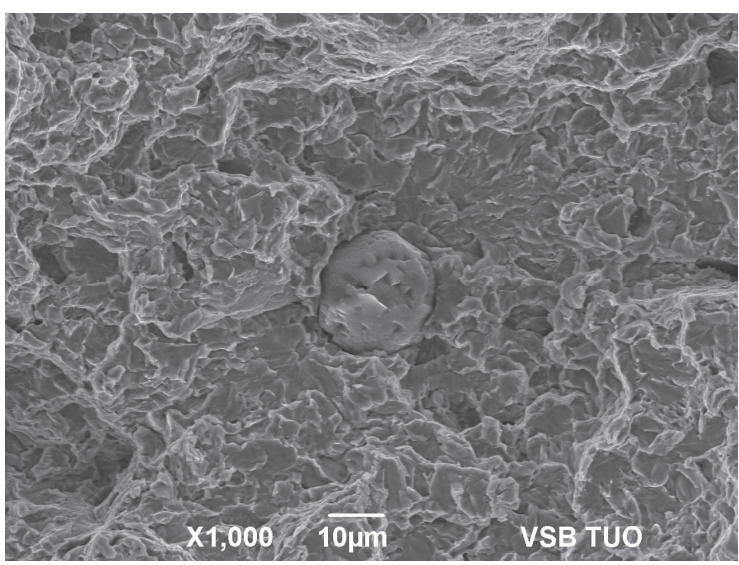

Figure 7 Detail of fracture surface after hydrogenation for 4 hours at $i=1 \mathrm{~mA} \cdot \mathrm{cm}^{-2}$. Fisheye in the centre of non-metallic complex inclusion (SEM-SE)

\section{CONCLUSIONS}

Compared to other types of steels used in the automotive industry, such as TRIP steels, DP600 steel can be considered as relatively resistant to hydrogen embrittlement. Globally, the DP600 steel exhibited only moderate susceptibility to hydrogen embrittlement during the experiment. The tensile strength did not change after hydrogenation. There was a slight increase at the yield strength at higher hydrogen densities. The degradation of mechanical properties was most pronounced by the decrease in elongation at fracture. Samples 
after hydrogen pre-charging showed embrittlement on average about $29 \%$. The effect of hydrogen embrittlement was also reflected in the character of fracture surfaces by the partial occurrence of quasicleavage fracture, most often around non-metallic inclusions.

\section{ACKNOWLEDGEMENTS}

This paper was created with the contribution of the projects Student Grant Competition "SP2019/27 Application of structural analysis, mechanical property testing and non-destructive defectoscopy methods at complex characterization of advanced materials" and "SP2019/43 Specific research in the metallurgical, materials and process engineering".

\section{REFERENCES}

[1] CONCEPTIÓN, Valeria L., LORUSSO, Hernán N. and SVOBODA, Hernán G. Effect of Carbon Content on Microstructure and Mechanical Properties of Dual Phase Steels. Procedia Materials Science. 2015, vol. 8, pp. 1047-1056.

[2] GRANBOM, YIva. Structure and mechanical properties of dual phase steels - An experimental and theoretical analysis. Doctoral thesis. KTH Industrial Engineering and management. 2010. ISSN 978-91-7415-740-6.

[3] DAVIES, R. G. Hydrogen Embrittlement of Dual-Phase Steels. Metallurgical transactions A. 1981, vol. 12, no. 9, pp. 1667-1672.

[4] DEPOVER, T., WALLAERT, E. and K. VERBEKEN. Fractographic analysis of the role of hydrogen diffusion on the hydrogen embrittlement susceptibility of DP steel. Materials Science and Engineering. 2016, vol. 649, pp. 201208.

[5] Dual phase steels. Arcelormittal.com [online]. Global Automotive \& Mobility Solutions [cit. 2019-04-12]. Available from https://automotive.arcelormittal.com/europe/products/AHSS/DP/EN.

[6] ISO 7539-7. Corrosion of metals and alloys - Stress corrosion testing - Part 7: Method for slow strain rate testing. 2005.

[7] VÁŇOVÁ, P., SOJKA, J., RADKOVSKÁ, T., KONEČNÁ, K., BRUCHÁČEK, A. and MATÝSEK, D. The influence of hydrogen on the mechanical properties of TRIP 780 steel. In METAL 2017: conference proceedings: 26th International Conference on Metallurgy and Materials: (reviewed version). Ostrava: TANGER, 2017, pp. 10271032. 